\title{
Atención temprana de niñas, niños y adolescentes con COVID-19
}

\section{Early care of children and adolescents with COVID-19}

\author{
Arturo Loredo-Abdala,* Lindsay C Cervantes-Pérez* \\ * Academia Mexicana de Pediatría y Centro de Estudios Avanzados sobre Maltrato Infantil y Prevención (CEAMI-P). México.
}

Recientemente se han publicado artículos de revisión para el manejo de niños con infección por el virus SARSCoV-2 que genera la enfermedad COVID-19. ${ }^{1}$ Por tal acción, el grupo médico del Centro de Estudios Avanzados sobre Maltrato Infantil-Prevención del Instituto Nacional de Pediatría (CEAMI-P-INP) mediante una carta al editor, señalamos un planteamiento general sobre las medidas que se deben tomar cuando se trata de atender niñas, niños o adolescentes sanos o con alguna comorbilidad (leucemia, cáncer, obesidad, daño renal, etcétera) y que no están sufriendo la infección aguda por el virus SARS-CoV-2. ${ }^{2}$

Como consecuencia del alargamiento de la pandemia en México, debido a que el número de casos clínicos y de muertes en adultos siguen aumentando, nos parece que es pertinente informar a la comunidad médica que atiende niñas, niños y adolescentes y que se encuentra laborando en un primer nivel de atención, cuál puede ser la estrategia diagnóstica y de tratamiento temprano en este grupo etario cuando recién han adquirido la infección viral.

En estos casos, lo más importante debe ser el reconocimiento clínico, lo más temprano posible, e iniciar un tratamiento sintomático. La aparición de nuevas variantes de las cepas COVID-19, las que aparentemente son más contagiosas, aunque su virulencia no se ha precisado con exactitud, probablemente pueden generar manifestaciones clínicas diferentes a las descritas anteriormente. $^{3-5}$
Hasta el momento no se ha podido precisar por qué la infección COVID-19 tiende a ser menos frecuente y grave en las personas menores de 18 años que en los adultos. Tampoco se ha establecido específicamente un cuadro clínico característico que le permita al médico de ese nivel de atención sospechar el diagnóstico tempranamente. En general, éste se hace cuando el compromiso cardiorrespiratorio y/o hematológico ya es muy evidente. ${ }^{6}$ Como consecuencia, los investigadores y/o autores no se aventuran a describir o presentar un cuadro clínico "típico". Ante esta realidad, el planteamiento de una estrategia temprana no se puede efectuar al no contar con el apoyo de una información específica y publicada en una revista médico-científica.

Si la comunidad médica se espera para cumplir con este requisito metodológico, es muy probable que la pandemia ya esté un poco controlada, puesto que se ha iniciado la aplicación de la vacuna específica; sin embargo, esta situación seguramente va a tardar un tiempo mayor en México si lo comparamos con otros países. Por lo tanto, precisar un cuadro clínico que se pueda considerar como el "estándar de oro" será demasiado tarde para los médicos que se encuentran en el primer nivel de atención. ${ }^{7-10}$

Ante tal ambigüedad clínica, sugerimos atender los datos clínicos, así como el manejo integral cuando se manifiestan inicialmente. En este momento es muy

Correspondencia: Dr. Arturo Loredo-Abdala, cainm_inp@hotmail.com

Citar como: Loredo-Abdala A, Cervantes-Pérez LC. Atención temprana de niñas, niños y adolescentes con COVID-19. Rev Mex Pediatr. 2021; 88(2): 78-80. https://dx.doi.org/10.35366/101283 
importante considerar a los adultos que los rodean (padres, otros familiares o personas diversas que conviven con ellos), los que aparentemente están sanos y no han guardado las medidas sanitarias básicas, para cerrar el círculo clínico "sospecha-diagnóstico-tratamiento".

La información que presentamos es el resultado de una experiencia clínica limitada. Nuestra intención es que solamente sea considerada por los médicos generales, médicos familiares y pediatras que se encuentran laborando en el primer nivel de atención, fuera de un centro hospitalario. Es una guía breve para el manejo inicial de las niñas, niños o adolescentes con COVID-19, pero que aún no presentan un problema respiratorio o hematológico, e inclusive, antes de que se tenga el resultado de una prueba de laboratorio confirmatoria de SARS-CoV-2 .

Para dar un valor más específico al cuadro clínico, se insiste en que el personal médico realice el siguiente interrogatorio:

1. Si los padres u otros familiares que viven en la misma casa no han mantenido la "cuarentena" de una manera adecuada.

2. Si alguno de ellos ha estado en contacto con alguna persona que ha sufrido la infección por COVID-19 en los últimos 14 días.

3. Si uno o ambos salen a trabajar y no ha sostenido estrictamente las medidas sanitarias universales.

4. Si uno o ambos presentan síntomas incipientes de COVID-19, pero sin confirmarse el diagnóstico.

5. El cuadro clínico de la persona adulta tiene una prueba positiva de SARS-CoV-2.

Cómo atender las siguientes manifestaciones clínicas:

1. Aparición súbita de febrícula $\left(37 \cdot 3-37.5^{\circ} \mathrm{C}\right)$ y rara vez fiebre alrededor de $38.3^{\circ} \mathrm{C}$. Aunque habitualmente los padres no le dan importancia a esta manifestación clínica se deben implementar las siguientes medidas:

a. Empleo de medios físicos para el control de la temperatura.

b. Si el niño está muy molesto se puede prescribir acetaminofén a la dosis de 10 a $15 \mathrm{mg} / \mathrm{kg} /$ dosis dividida en cuatro tomas.

2. Aparición súbita de rinorrea escasa y discreto dolor de garganta.
Las acciones recomendadas son:

a. Aseo nasal varias veces al día con agua corriente o solución salina.

b. Cepillado de dientes de tres a cuatro veces al día.

c. El médico decidirá el empleo de un antihistamínico, a fin de reducir la rinorrea y evitar que el niño se toque frecuentemente la nariz.

3. Dolor físico, cansancio y que el niño se acueste sin pedirlo.

Para el control del dolor se puede prescribir acetaminofén a la dosis ya señalada.

4. La aparición súbita de vómito y diarrea de corta duración.

Las medidas propuestas son:

a. Suspender la ingesta de alimentos o líquidos por 4 a 6 horas.

b. El médico prescribirá, en caso necesario, el empleo de un medicamento antiemético.

5. Para el control del proceso diarreico:

a. Suspender la vía oral por 4 a 6 horas.

b. Suspender la ingesta de lácteos (leche, yogur, queso, crema) para evitar o manejar un cuadro de intolerancia a la lactosa.

c. Después del ayuno ofrecer al niño suero oral en pequeñas cantidades, antes de iniciar la dieta normal.

d. Inicio de ingesta de alimentos con una dieta astringente (arroz, pollo, consomé de pollo, principalmente).

6. Para la protección de la mucosa gástrica:

a. Evitar la ingesta de alimentos irritantes.

b. Se puede prescribir omeprazol; dosis de 0.5 a $1.5 \mathrm{mg} / \mathrm{kg} /$ dosis, una vez al día por siete días.

7. Se puede emplear vitamina A, C, D y zinc, pero no se conoce su verdadero beneficio.

8. No se deben prescribir medicamentos, ya que no han probado ser eficaces para prevenir o tratar la enfermedad, incluyendo los antivirales.

9. En todos los casos es indispensable implementar y seguir las medidas sanitarias universales. ${ }^{1,11}$ Éstas son: 
a. Mantener sana distancia efectiva, en cualquier lugar y momento.

b. Uso constante de cubrebocas, particularmente en lugares cerrados.

c. Lavado frecuente de manos con jabón o aplicación de gel antibacterial.

d. Lavado de dientes de tres a cuatro veces al día.

e. Baño diario.

f. Exposición al sol diariamente por 10 a 15 minutos.

La aparición de nuevas cepas de SARS-CoV-2 en Sudáfrica, Brasil y probablemente en México, pueden ser factores que coadyuven a la persistencia de la pandemia en México. Esperamos que con la aplicación de la vacuna en los padres, familiares o adultos que pueden convivir con los menores, seguramente disminuirá el número de pacientes pediátricos infectados.

\section{REFERENCIAS}

1. Montaño-Luna VE, Miranda-Novales MG. Actualización del manejo clínico de COVID-19 en pediatría: a un año de pandemia. Rev Mex Pediatr. 2021; 88(1): 31-45. doi: 10.35366/99417.

2. Loredo-Abdala A, Galván-Díaz C, Gómez-Aguilar N, CervantesPérez L, Ojeda-Pérez P, Casas-Muñoz A. Carta al editor respecto del suplemento 1, 2020 de la pandemia por SARS-CoV-2. Acta Pediatr Mex. 2020; 41: 235-239.
3. Kirby T. New variant of SARS-CoV-2 in UK causes surge of COVID-19. Lancet Respir Med. 2021; 9(2): e20-e21.

4. Wise J. COVID-19: new coronavirus variant is identified in UK. BMJ. 2020; 371: m4857. doi: 10.1136/bmj.m4857.

5. Viner RM, Mytton OT, Bonell C, Melendez-Torres GJ, Ward J, Hudson $L$ et al. Susceptibility to SARS-CoV-2 infection among children and adolescents compared with adults: a systematic review and meta-analysis. JAMA Pediatr. 2021; 175(2): 143-156.

6. Swann O, Holden K, Turtle L, Pollock L. Clinical characteristics of children and young people admitted to hospital with covid-19 in United Kingdom: prospective multicentre observational cohort study. BMJ. 2020; 370: m3249.

7. Liguoro I, Pilotto C, Bonanni M et al. SARS-CoV-2 infection in children and newborns: a systematic review. Eur J Pediatr. 2020; 179(7): 1029-1046. Available in: https://doi.org/10.1007/s00431-020-03684-7

8. Hoang A, Chorath K, Moreira A, Evans M, Burmeister-Morton $F$, Burmeister $F$ et al. COVID-19 in 7780 pediatric patients: A systematic review. E Clinical Medicine. 2020; 26: 1088-1095. doi: 10.1016/j.eclinm.2020.100433.

9. Zimmermann $P$, Curtis N. Coronavirus infections in children including COVID-19. Pediatr Infect Dis J. 2020; 39(5): 355-368.

10. Lee B, Raszka WV Jr. COVID-19 transmission and children: the child is not to blame. Pediatrics. 2020; 146: e2020004879. Available in: https://doi.org/10.1542/peds.2020-004879

11. Calva y Rodríguez RG, Robledo-Galván A, Vigueras-Rendón A et al. Normas para la protección al salir de casa ante la pandemia COVID-19. Rev Mex Pediatr. 2020; 87(3): 119-120. doi: $10.35366 / 94844$.

Conflicto de intereses: Los autores declaran que no tienen. 